\title{
Repression of phosphoinositide-dependent protein kinase 1 expression by ciglitazone via Egr-1 represents a new approach for inhibition of lung cancer cell growth
}

SWei Sunny Hann ${ }^{1 *}$, Qing Tang ${ }^{1}$, Fang Zheng ${ }^{1}$, Shunyu Zhao', Jianping Chen ${ }^{2}$ and ZhiYu Wang ${ }^{2}$

\begin{abstract}
Background: Peroxisome proliferator-activated receptors gamma (PPARY) ligands have been shown to inhibit the growth of non-small cell lung cancer (NSCLC) cells. However, the mechanisms underlying this effect remain incompletely elucidated.

Methods: Cell proliferation and apoptosis were measured by cell viability, MTT and caspase3/7 activity assays. Phosphorylation/protein expression and gene silence/overexpression of AMPKa, phosphoinositide-dependent protein kinase 1 (PDK1), Egr-1 and PPARY were performed by Western blot and siRNA/transfection assays. Dual-Luciferase Reporter Kit was used to measure the PPAR response elements (PPRE) reporter and PDK1 promoter activities, and ChIP assay was used to detect the Egr-1 protein binding to the DNA site in the PDK1 gene promoter.

Results: We found that ciglitazone, one synthetic PPARY ligand, inhibited growth and induced apoptosis of NSCLC cells through decreased expression of PDK1, which was not blocked by GW9662 (a specific PPARY antagonist). Overexpression of PDK1 overcame the effect of ciglitazone on cell growth and caspase 3/7 activity. Ciglitazone increased the phosphorylation of AMPKa and c-Jun N-terminal kinase (JNK), and the inhibitor of AMPK (compound C), but not JNK (SP600125), reversed the effect of ciglitazone on PDK1 protein expression. Ciglitazone reduced PDK1 gene promoter activity, which was not observed in cells exposed to compound C, but not silenced of PPARY siRNA. Combination of ciglitazone and metformin further reduced PDK1 expression and promoter activity. Furthermore, we showed that ciglitazone induced the protein expression of Egr-1, which was not observed in cells silencing of AMPKa. Moreover, silencing of Egr-1 abrogated the effect of ciglitazone on PDK1 promoter activity and cell growth. On the contrary, overexpression of Egr-1 enhanced the effect of ciglitazone on PDK1 gene promoter activity. ChIP assays demonstrated that ciglitazone induced Egr-1 protein bind to the specific DNA site in the PDK1 gene promoter.

Conclusion: Collectively, our results demonstrate that ciglitazone inhibits PDK1 expression through AMPKa-mediated induction of Egr-1 and Egr-1 binding to the specific DNA site in the PDK1 gene promoter, which is independent of PPARY. Activation of AMPKa by metformin enhances the effect of ciglitazone. In turn, this leads to inhibition of NSCLC cell proliferation.
\end{abstract}

Keywords: Human lung adenocarcinoma cell, Egr-1, PDK1, Ciglitazone, AMPKa, Metformin

\footnotetext{
*Correspondence: swhan2010@live.com

'University of Guangzhou Traditional Chinese Medicine, Guangdong Academy of Traditional Chinese Medicine, Guangdong Provincial Hospital of Chinese Medicine, Guangzhou, Guangdong Province, China 510120

Full list of author information is available at the end of the article
} 


\section{Background}

Lung cancer remains the leading cause of cancer-related mortality in the United States, and 30\% to $40 \%$ of newly diagnosed patients with non-small cell lung cancer (NSCLC) present with regionally advanced and unresectable stage III disease [1]. Despite recent advances in understanding the molecular biology of lung cancer and the introduction of multiple new chemotherapeutic agents for its treatment, the poor outcomes related to lung cancer have not changed substantially $[2,3]$. This justifies the continuing search for agents with therapeutic potential against NSCLC.

Peroxisome proliferator-activated receptors (PPARs isotypes $\alpha, \beta / \delta, \gamma)$ are ligand-inducible nuclear transcription factors that heterodimerize with retinoid $\mathrm{X}$ receptors and bind to PPAR response elements (PPRE) located in the promoter region of PPAR target genes [4]. The role of PPAR $\gamma$, one PPAR isotype, has been extensively studied thanks to the availability of synthetic PPARY agonists including antidiabetic drugs, such as rosiglitazone, ciglitazone, and pioglitazone [5]. These drugs are also effective in regulating cell activation, differentiation, proliferation, and apoptosis through both PPAR $\gamma$-dependent and -independent signaling [6,7]. However, the detailed mechanisms responsible for these effects remain incompletely elucidated.

Stress-activated protein kinase/c-Jun N-terminal kinase (SAPK/JNK) is a mitogen-activated protein kinase family member that is activated by diverse stimuli and plays a critical role in regulating cell fate, being implicated in a multitude of diseases ranging from cancer to neurological, immunological and inflammatory conditions. JNK signaling is required for normal mammary gland development and has a suppressive role in mammary tumorigenesis [8]. AMP-activated protein kinase (AMPK), a heterotrimeric protein complex with serine/threonine kinase activity, has been involved in the regulation of a number of physiological processes including $\beta$-oxidation of fatty acids, lipogenesis, protein and cholesterol synthesis, as well as cell cycle inhibition and apoptosis. AMPK has been shown to act upstream and downstream of known tumor suppressors. However, whether AMPK acts as a bona fide tumor suppressor or a oncogene and, of particular importance, if AMPK should be targeted for activation or inhibition during cancer therapy, is controversial [9]. Early growth response-1 (Egr-1) is a Cys2-His2-type zinc-finger transcription factor. A broad range of extracellular stimuli is capable of activating Egr-1, thus mediating growth, proliferation, differentiation or apoptosis. Egr-1 is, therefore, participating in the progression of a variety of diseases such as atherosclerosis or cancer. A growing body of evidence suggests that Egr-1 functions as a tumor suppressor [10-12].

In an effort to explore the anti-tumor effects of ciglitazone on potential targets, we turned our attention to 3-phosphoinositide-dependent protein kinase 1 (PDK1), a master regulator of signal cascades that is involved in suppression of apoptosis and promotion of tumor growth including lung cancer [13]. Reduction of PDK1 by small interfering RNA (siRNA) in several cancer cells results in significant growth inhibition [14-17]. These observations suggest that PDK1 can be used as a target for cancer therapies.

Here, we report that ciglitazone inhibits NSCLC proliferation by inhibiting PDK1 expression through activation of AMPK $\alpha$ and induction of Egr-1 that is independent of PPAR $\gamma$.

\section{Results}

Ciglitazone decreased growth and induced apoptosis in lung cancer cells, and inhibited PDK1 protein expression independent of PPAR $\gamma$

We first examined the effect of ciglitazone on growth and apoptosis of lung cancer cells. We found that ciglitazone inhibited growth of lung cancer cell H1650 in the time- and dose-dependent manner, with significant inhibition observed at $20 \mu \mathrm{M}$ at $48 \mathrm{~h}$ (Figure 1A, upper panel). Similar results were also observed in other NSCLC cell lines (Figure 1A, lower panel). We also showed that ciglitazone induced caspase 3/7 activity in $\mathrm{H} 1650$ cells indicating increase in apoptosis (Figure 1B). We then examined whether ciglitazone affected the expression of PDK1. We found that ciglitazone inhibited PDK1 protein expression in a time- and dose-dependent manner, with an effective response of $20 \mu \mathrm{M}$ at $24 \mathrm{~h}$ in H1650 cells (Figure 1C). Reduction of PDK1 protein expression by ciglitazone was also found in other NSCLC cell lines (Figure 1D).

We then tested whether the effects of ciglitazone on PDK1 were mediated through the activation of PPAR $\gamma$. We showed that, while ciglitazone increased the PPRE luciferase activity (activation of PPAR) (Figure 2A), the effects of ciglitazone on PDK1 expression were not eliminated in the presence of GW9662, a specific PPAR $\gamma$ antagonist (Figure 2B) and in cells (H1299 and H1650) silencing of PPARY (not shown). The result suggests that PPAR $\gamma$-independent signals mediate the effect of ciglitazone on PDK1 protein expression.

Next, to test whether ciglitazone affects cell growth through PDK1-mediated signals, we blocked the PDK1 gene using PDK1 siRNA. We showed that knockdown of PDK1 significantly reduced PDK1 production, while the control siRNA had no effect (Figure 2C, upper panel). Cells exposed to PDK1 siRNA showed a slight reduction in cell proliferation at baseline; however, they showed significant reduction in growth in the presence of ciglitazone as determined by cell viability assay (Figure 2C, lower panel). Overexpression of PDK1 has been reported to correlate with tumor progression [15]. We found that overexpression of PDK1 abrogated the effect of ciglitazone 

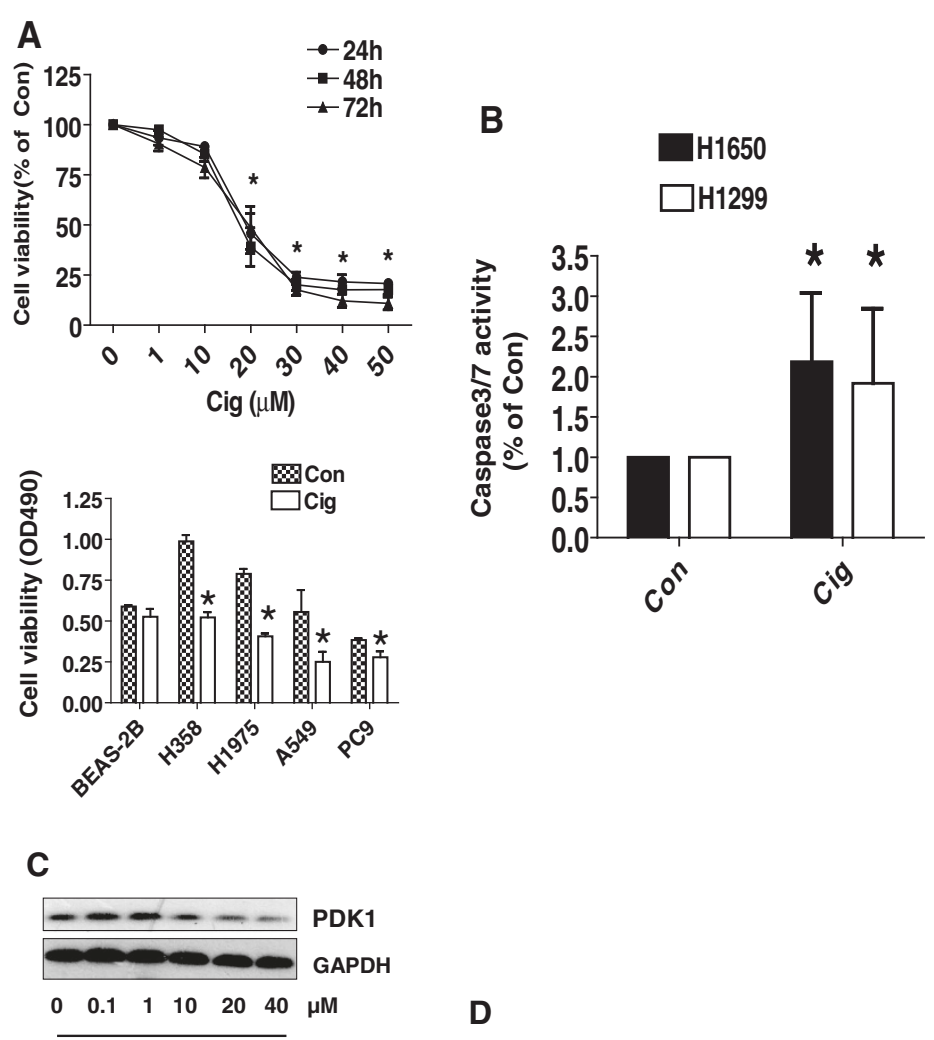

Cig, $24 \mathrm{~h}$
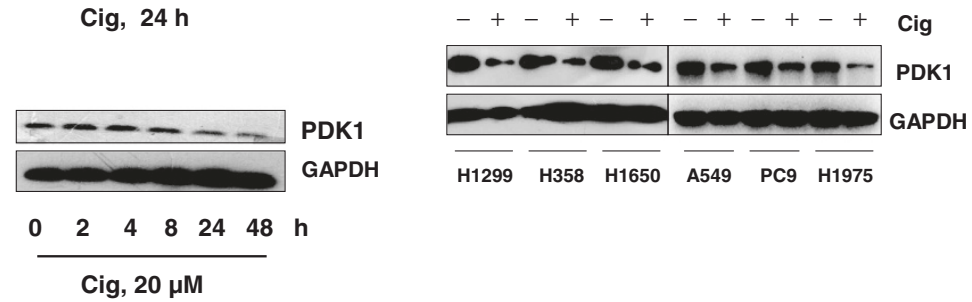

H1299 $\quad$ H358 H1650 A549 PC9 H1975

Cig, $20 \mu \mathrm{M}$

Figure 1 Ciglitazone decreased growth and induced apoptosis in lung cancer cells. A, H1299 cells were treated with increased concentrations of ciglitazone for up to $72 \mathrm{~h}$ (upper panel). NSCLC cells indicated were treated with ciglitazone ( $20 \mu \mathrm{M})$ or up to $48 \mathrm{~h}$ (lower panel). The cell viability was determined using the MTT assay as described in the Materials and Methods section in three separate experiments. B, Caspase 3/7 activity assay was performed on $\mathrm{H} 1299$ cells treated with or without ciglitazone for $48 \mathrm{~h}$. Relative caspase 3/7 activity is indicated as percentage of untreated control cells. Results represent those obtained in three experiments. *indicates significant difference as compared to the untreated control group $(P<0.05)$. C, Cellular protein was isolated from H1299 cells that were cultured with increased concentrations of ciglitazone for up to $24 \mathrm{~h}$ (upper), or with ciglitazone $(20 \mu \mathrm{M})$ for indicated period of time (lower), followed by Western blot. D. Cellular protein were isolated from NSCLC cells (H1299, PC9, A549, H1957, H358 and H1650) that were cultured with ciglitazone (20 $\mu \mathrm{M})$ for up to 24, followed by Western Blot.

on cell growth (Figure 2D, lower panel) and caspase 3/7 activity (Figure 2E). Transfection with PDK1 expression vector was confirmed by Western blot (Figure 2D-E, upper panel). Together, this suggested that ciglitazone not only inhibited growth but also increased apoptosis of lung cancer cells through, at least in part, the inhibition of PDK1.

The role of AMPKa and SAPK/JNK in mediating the effect of ciglitazone on PDK1 protein expression

Studies by this group and others also demonstrated a role for AMPK in mediating the effect of PPAR ligands, such as thiazolinediones (TZDs) compounds, in different cell systems $[18,19]$. We showed that ciglitazone increased phosphorylation of AMPK $\alpha$ and SAPK/JNK with maximal effect observed at 2-4 h in H1650 cells (Figure 3A-B). Interestingly, the inhibitors of AMPK, compound $C$, but not of SAPK/JNK, SP600125, blocked the inhibitory effect of ciglitazone on PDK1 protein expression in both H1650 and H1299 cells (Figure 3C). Similarly, silencing of AMPK $\alpha$ abrogated the effect of ciglitazone on PDK1 protein (Figure 3D). This indicates the specificity of AMPK $\alpha$ activation in this process. Interestingly, combination treatment of ciglitazone and metformin, an activator of AMPK, further reduced the PDK1 protein expression (Figure 3E). 


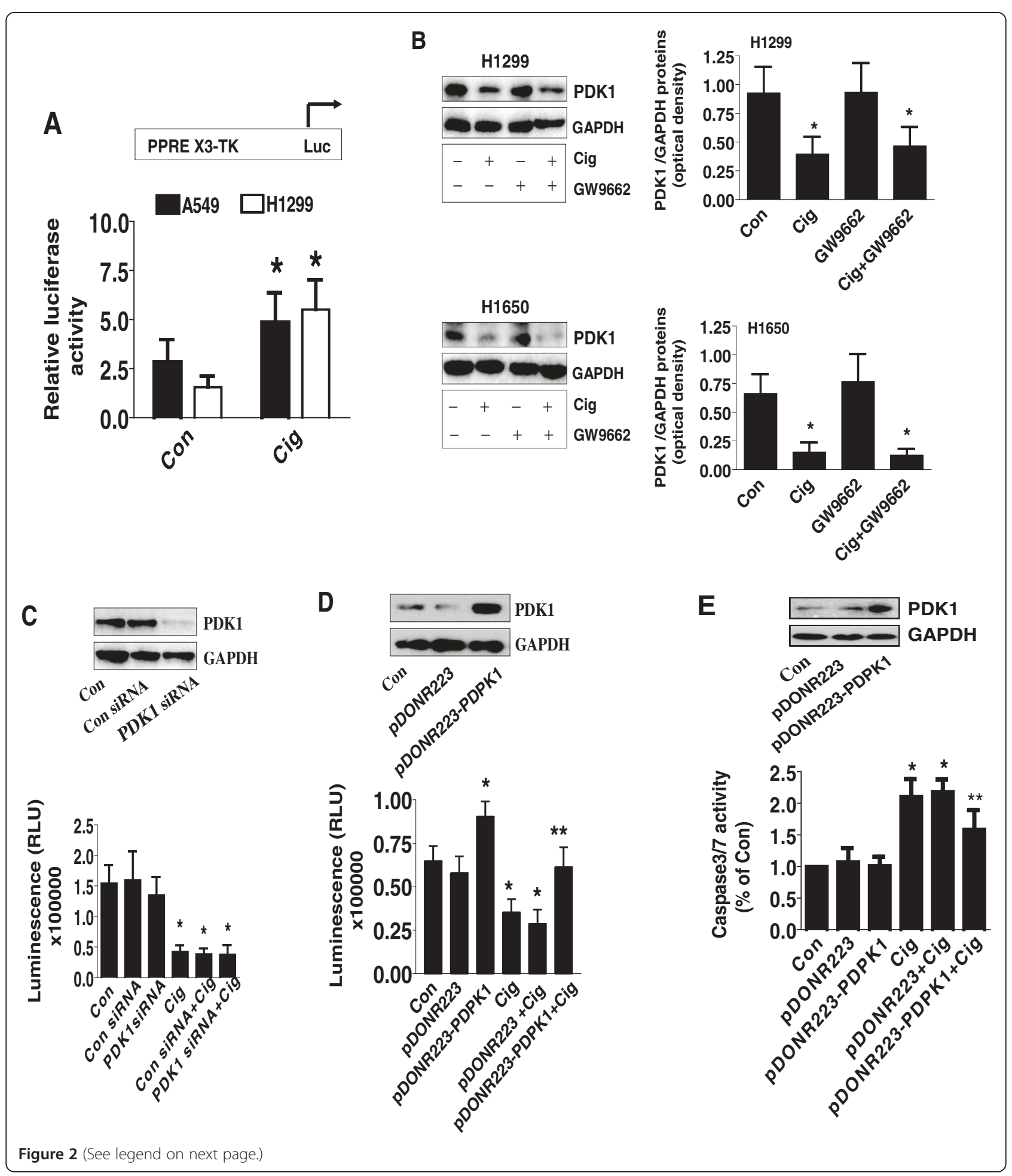


(See figure on previous page.)

Figure 2 Ciglitazone inhibited PDK1 protein expression independent of PPAR $\mathbf{A}$. A 1299 and H1650 cells were transfected with control or PPRE X3-TK-luc reporter (from Addgene) for $24 \mathrm{~h}$, followed by treating with ciglitazone for an additional $24 \mathrm{~h}$. Afterwards, the Luciferase reporter activity was measured using Luciferase Assay System (Promega) according to manufacturer's instructions. The bars represent the mean \pm SD of at least three independent experiments for each condition. *indicates significant difference as compared to the untreated control group (P<0.05). B, Cellular protein was isolated from H1299 and H1650 cells cultured for $1 \mathrm{~h}$ in the presence or absence of GW9662 (20 $\mu$ M) before exposing the cells to ciglitazone $(20 \mu \mathrm{M})$ for an additional 24 h, then subjected to Western blot analysis. C, H1299 cells were transfected with control or PDK1 siRNA $(80 \mathrm{nM})$ for $40 \mathrm{~h}$, followed by exposing the cells to ciglitazone $(20 \mu \mathrm{M})$ for an additional $24 \mathrm{~h}$. Afterwards, the luminescence of viable cells was detected using Cell Titer-Glo Luminescent Cell Viability Assay kit. D-E, H1299 cells were transfected with the control and PDK1 expression vectors using the oligofectamine reagent according to the manufacturer's instructions. After $24 \mathrm{~h}$ of incubation, cells were treated with or without ciglitazone for an additional $24 \mathrm{~h}$. Afterwards, the luminescence of viable cells was detected using Cell Titer-Glo Luminescent Cell Viability Assay kit (D). In separate experiment, the relative caspase 3/7 activity (E) is indicated as percentage of untreated control cells. The bars represent the mean \pm SD of at least four independent experiments for each condition. Insert on the top panel shows a Western blot for PDK1 protein. *indicates significant difference as compared to the untreated control group $(P<0.05)$. ${ }^{*}$ Indicates significance of combination treatment as compared with ciglitazone alone $(P<0.05)$.

\section{Ciglitazone decreases PDK1 promoter activity independent of PPARY activation}

We also examined if the effects of ciglitazone on PDK1 expression occurred at the transcriptional level. As shown in Figure 4A, the PDK1 gene promoter contains multiple transcription factor binding sites including PPRE, Egr-1, nuclear factor- $\mathrm{kB}(\mathrm{NF}-\mathrm{kB})$ and $\mathrm{p} 53$, among others. We found that NSCLC cells transfected with wild-type PDK1 promoter-luciferase reporter construct showed decreased activity when exposed to ciglitazone (Figure 4B). As expected, metformin enhanced the inhibitory effect of ciglitazone (Figure 4B).

Next, we assessed whether PPAR $\gamma$ activation played a role in mediating the effect of ciglitazone on PDK1 promoter activity. The effect of ciglitazone on inhibition of PDK1 promoter activity was not abrogated by PPAR $\gamma$ siRNA (Figure 4C, lower panel). Note that PPAR $\gamma$ siRNA blocked PPAR $\gamma$ protein expression (Figure 4C, upper panel). As expected, we found that compound $\mathrm{C}$ reduced the effect of ciglitazone on PDK1 promoter activity (Figure 4D).

\section{The role of transcription factor Egr-1 in mediating the effect of ciglitazone on expression of PDK1 and cell growth} We further tested the role of the transcription factors in mediating the effect of ciglitazone on PDK1 expression in human lung carcinoma cells. We showed that ciglitazone significantly induced the expression of Egr-1 protein in a time-dependent manner, while it had little effect on p65 and p53 (Figure 5A, upper panel). Note that a synergy was observed in the combination of ciglitazone and metformin treatment (Figure 5A lower panel). Interestingly, we also found that silencing of AMPK $\alpha$ abolished the effect of ciglitazone on Egr-1 protein expression, further suggesting the critical role of AMPK $\alpha$ activation in this process (Figure 5B). Next, we found that while cells transfected with Egr-1 siRNA slightly increased PDK1 promoter activity at baseline, it greatly antagonized the inhibitory effect of ciglitazone on PDK1 promoter activity.
Note that the control siRNA had no effect (Figure 5C, lower panel). Egr-1 siRNA reduced the production of Egr-1 protein (Figure 5C, upper panel). Furthermore, it eliminated the ciglitazone-reduced PDK1 protein expression, whereas the control siRNA had no effect (Figure 5D). Consistent with these findings, we found that cells transfected with Egr-1 siRNA blocked the inhibitory effects of ciglitazone on cell growth (Figure 5E). The control siRNA had no effect.

However, cells co-transfected with an Egr-1 expression vector showed little or no synergistic effect on PDK1 promoter activity (Figure 6A), suggesting the specificity of Egr-1. Next, by ChIP assays, we showed that ciglitazone induced Egr-1 protein binding to the Egr-1 DNA site in the $P D K 1$ gene promoter (Figure $6 \mathrm{~B}$ ).

\section{Discussion}

The expression of PPAR $\gamma$ and the effects of PPAR $\gamma$ ligands on cell growth have been extensively studied in many carcinoma cell types including lung $[6,20]$. However, the exact mechanisms mediating the effects of PPAR $\gamma$ ligands on cell growth inhibition are not fully understood. We have found that ciglitazone, a TZD and one of the synthetic PPAR ligands, inhibited growth and induced apoptosis of NSCLC cells through reduction of PDK1, a kinase and master regulator of a number of downstream signal cascades that are involved in suppression of apoptosis and promotion of tumor growth including lung cancer [13,21]. Inhibition of PDK1 in several cancer cells results in significant cell growth inhibition [14-17]. These observations suggest that PDK1 can be considered as a key mediator of neoplasia and a promising anticancer target. This result, together with the finding that exogenous PDK1 diminishes the effect of ciglitazone on cancer cell growth, suggests a critical role of PDK1 in this process.

The concentrations of ciglitazone used here, found significantly inhibition of PDK1 gene expression and cell growth, are consistent or even lower with those reported 


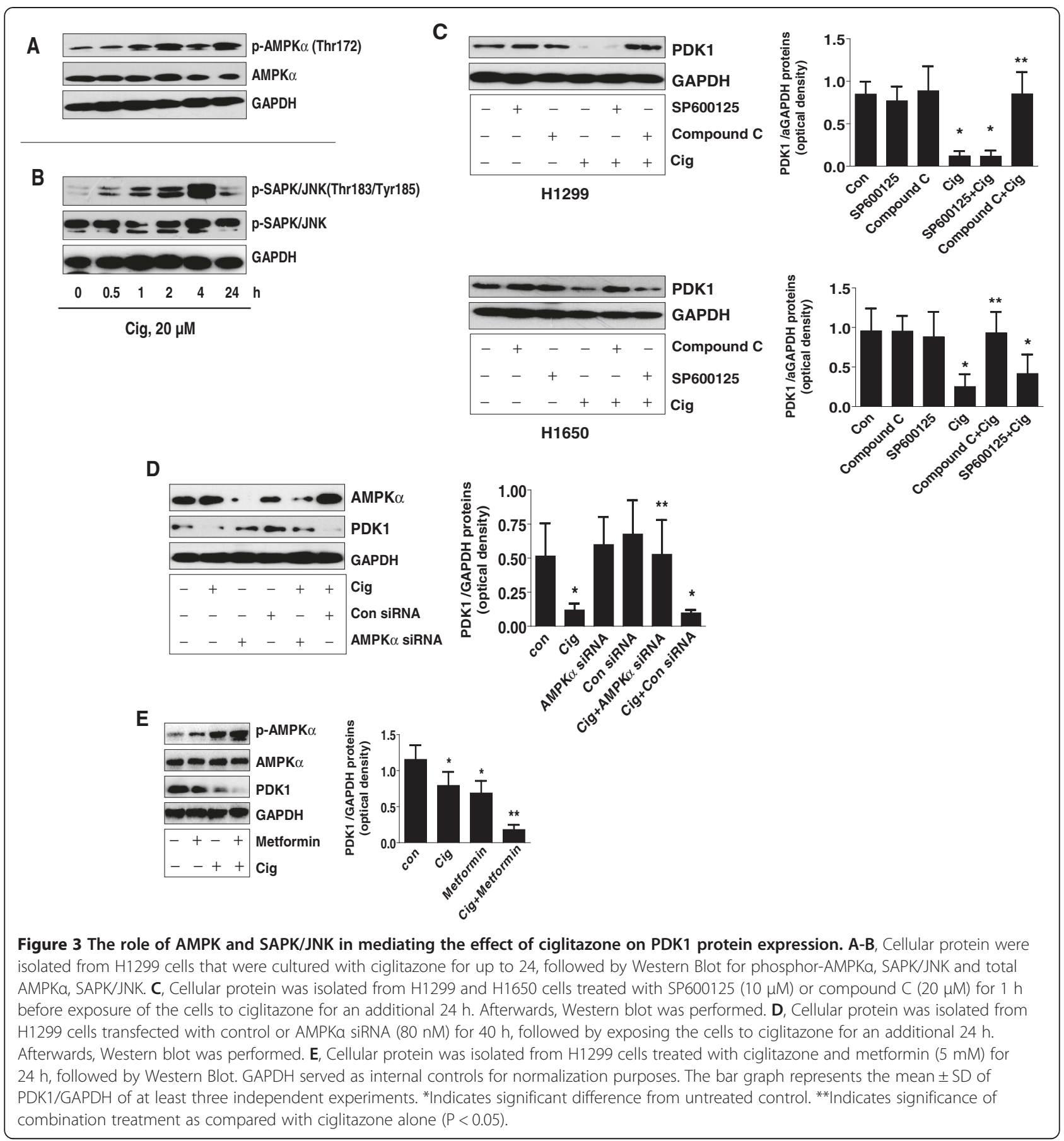

by others which showed a significant effect on cell growth and apoptosis at clinically achievable concentrations [22-25]. For example, ciglitazone inhibited the growth of androgen-dependent and -independent human prostate cancer cells starting at 10 and reached maximal at even $45 \mu \mathrm{M}$ concentrations [23]. In another study, ciglitazone showed to significantly inhibit cell viability and proliferation of brain tumor stem cells starting at 5 and continued to $25 \mu \mathrm{M}$ concentration [25].
We demonstrated that ciglitazone inhibited the expression of PDK1 protein independent of PPAR $\gamma$ signals. Consistent with this, the PPAR $\gamma$-independent signals mediating the effects of PPAR $\gamma$ ligands on gene expression and cell proliferation including lung cancer have been shown in other studies [24,26,27] although PPAR $\gamma$-dependent signals were observed [28,29]. We reasoned that targeting PDK1 may also involve such mechanisms by which ciglitazone inhibits NSCLC cell 


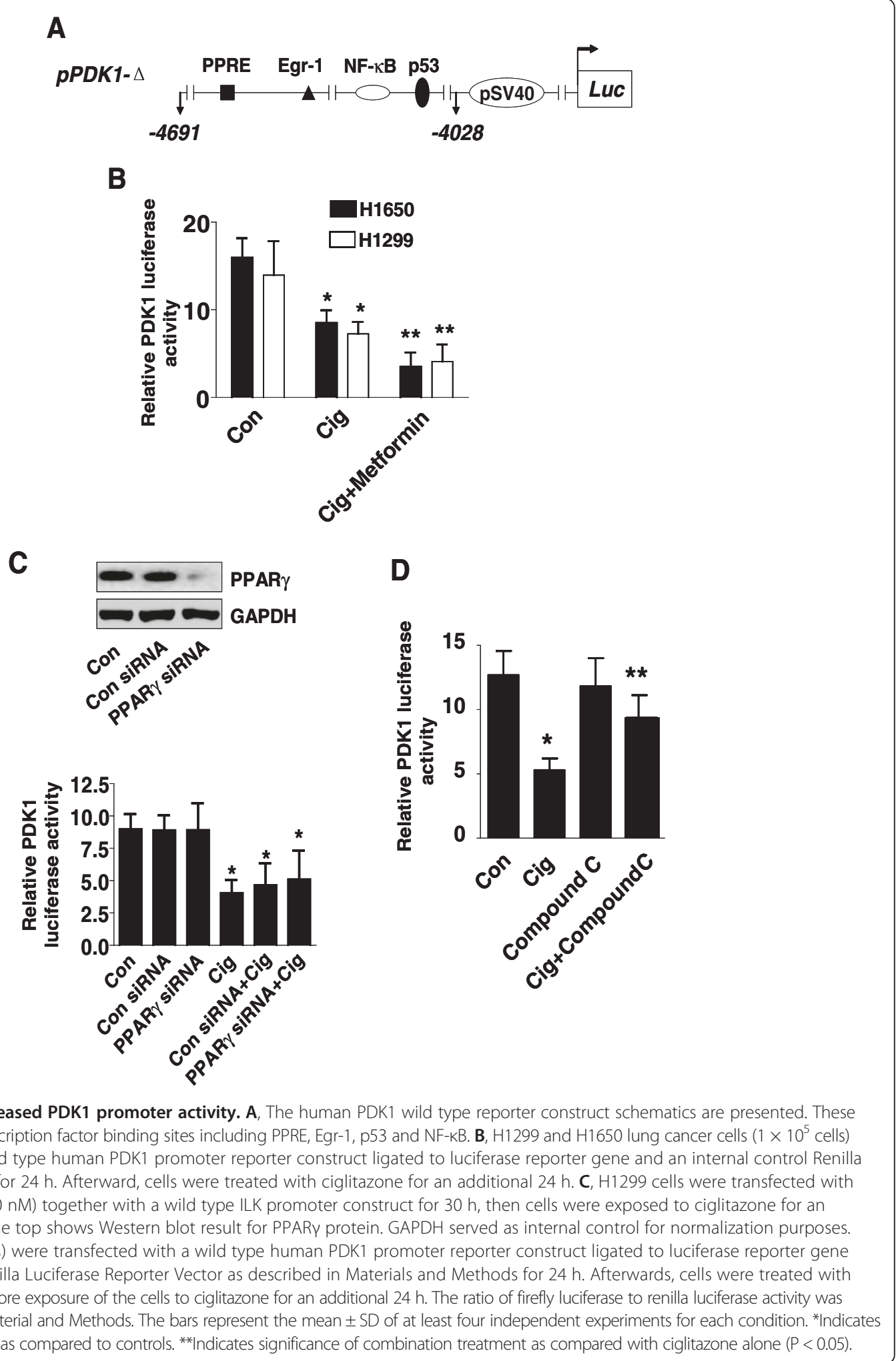

growth. Given the fact that silencing of the PPARy gene by siRNA had no effect on blockage of the effect of ciglitazone on PDK1 promoter activity, additional experiments are required to explore the contributions of PPAR $\gamma$-independent mechanisms in these processes. 


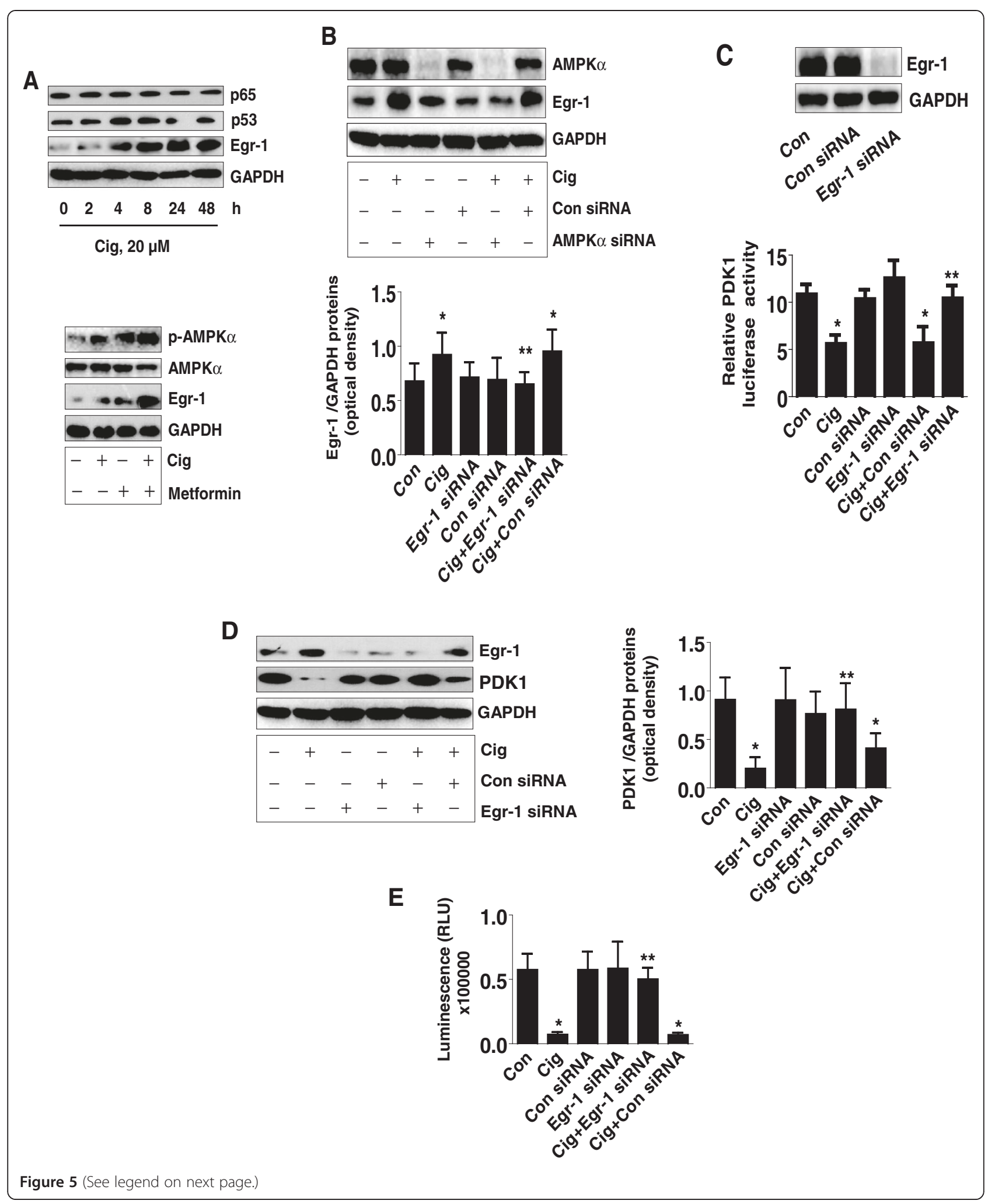


(See figure on previous page.)

Figure 5 Ciglitazone induces Egr-1 protein expression; silencing of Egr-1 abrogates the effect of ciglitazone on PDK1 promoter activity, protein expression and cell proliferation. A, Cellular proteins were isolated from H1299 cells treated with ciglitazone (20 $\mu \mathrm{M}$ ) for the indicated time period (upper panel) or with metformin (5 mM) for $24 \mathrm{~h}$ (lower panel). Afterwards, Western blot analyses were performed for detecting Egr-1, p65 and p53 proteins. B, H1299 cells were transfected with control or AMPKa siRNA (80 nM) for 30 h before exposing the cells to ciglitazone $(20 \mu \mathrm{M})$ for an additional $24 \mathrm{~h}$ followed by Western blot. C, H1299 cells were transfected with control or Egr-1 siRNA (80 nM) together with a wild type PDK1 promoter construct for $30 \mathrm{~h}$, then cells were exposed to ciglitazone (20 $\mathrm{MM}$ ) for an additional $24 \mathrm{~h}$. Insert shows the Western blot result for Egr-1 protein. D, H1299 cells were transfected with control or Egr-1 siRNA ( $80 \mathrm{nM}$ ) for $30 \mathrm{~h}$ before exposing the cells to ciglitazone (20 $\mu$ M) for an additional 24 h, followed by Western blot. E, H1299 cells were transfected with control or Egr-1 siRNA ( 80 nM) for 30 h before exposure of the cells to ciglitazone $(20 \mu \mathrm{M})$ for an additional $24 \mathrm{~h}$. Afterwards, the luminescence of viable cells was detected using Cell Titer-Glo Luminescent Cell Viability Assay kit. The bars represent the mean \pm SD of at least four independent experiments for each condition. *Indicates significant difference as compared to the control. **Indicates significance of combination treatment as compared with ciglitazone alone $(\mathrm{P}<0.05)$.

Interestingly, PDK1 knockdown alone did not affect cell proliferation significantly. However, inhibition of PDK1 in the setting of ciglitazone treatment resulted in largely growth inhibition. This suggests that other factors are important for control of NSCLC cell proliferation. It also suggests that the growth inhibitory effects of ciglitazone may occur by concomitant actions on pathways other then PDK1. Report shown that ciglitazone exerts effects on several other targets that were implicated in control of lung cancer growth [30,31].

In this study, we showed that activation of AMPK $\alpha$ played a vital role in mediating the effect of ciglitazone on PDK1 expression. In addition, activation of AMPK enhanced the effect of ciglitazone on PDK1 expression and promoter activity. Data demonstrated that synthetic PPAR $\gamma$ ligands regulated several kinase signaling pathways including AMPK in different cells [32,33]. Activation or inactivation of AMPK has been shown to link synthetic PPAR $\gamma$ agonists-mediated signaling to the transcriptional regulation of genes that are crucial for cell growth inhibition $[32,34]$. Considering the recent data for the dual role of AMPK [9], we believed that more dedicated studies are required to further elucidate the biological function and relevant signaling of this kinase.

Having demonstrated the important role of PDK1, we further investigated whether the ciglitazone-mediated downregulation of PDK1 reflected inhibition of transactivation of the PDK1 gene. Our results suggested that increased Egr-1 protein expression and binding to the upstream areas of $P D K 1$ gene promoter played an important role in mediating the effect of ciglitazone. Knockdown of Egr-1 abrogated the effect of ciglitazone on PDK1 expression and on cell proliferation, whereas overexpression of Egr-1 had no further effect of ciglitazone on PDK1 promoter activity confirming the inhibitory property of this transcription factor. It also suggested the specificity of Egr-1 played in this process. To our knowledge, the role of Egr-1 in regulation of PDK1 expression has never been reported. Egr-1 functions as a tumor suppressor in many cancers [10-12]. Loss of Egr-1 expression has been associated with invasion and anti-apoptotic events, whereas overexpression of Egr-1 suppressed the tumorigenicity and metastatic potential in several cancer cells including lung $[34,35]$. However, opposite role of Egr-1 were also found in several studies [36,37]. Thus Egr-1 is considered to play dual roles depending on the cell types and environment. One study showed that several PPAR $\gamma$ ligands including TZD induced the expression of Egr-1 through PPAR $\gamma$-independent pathway in breast cancer cells [38]. Thus, other factors responsible for this effect (in addition to Egr-1) need further exploration. ChIP assays showed that Egr-1 protein occupancy of the Egr-1 sites in the upstream areas of PDK1 gene promoter was enhanced by exposure of cells to ciglitazone. Further studies are required by site-directed mutagenesis experiments to confirm this. Moreover, the detail mechanisms responsible for the effect of metformin in this process needs to be determined.

\section{Conclusion}

Our results demonstrate that ciglitazone inhibits PDK1 expression through AMPK $\alpha$-mediated induction of Egr-1 protein expression and Egr-1 binding to specific DNA sequences in the $P D K 1$ gene promoter, which is independent of PPAR $\gamma$ activation. Activation of AMPK $\alpha$ by metformin enhances the effect of ciglitazone on Egr-1 and PDK1 protein expression. In turn, this leads to inhibition of NSCLC cell proliferation (Figure 6C). This study provides a novel mechanism by which the antidiabetic drug inhibits human lung cancer cell growth, and targeting the PDK1 may be a potential therapeutic strategy for inhibition of lung cancer growth.

\section{Materials and methods}

\section{Culture and chemicals}

The human NSCLC cell lines A549, H1650, PC9, H1975, H1299 and H358 were obtained from the Cell Line Bank at the Laboratory Animal Center of Sun Yat-sen University starting March 2012 (Guangzhou, China) and grown in RPMI-1640 medium supplemented with $10 \%$ heatinactivated FBS, HEPES buffer, $50 \mathrm{IU} / \mathrm{mL}$ penicillin/ streptomycin, and $1 \mu \mathrm{g}$ amphotericin (complete medium). All cell lines have been tested and authenticated for absence of Mycoplasma, genotypes, drug response, and morphology 

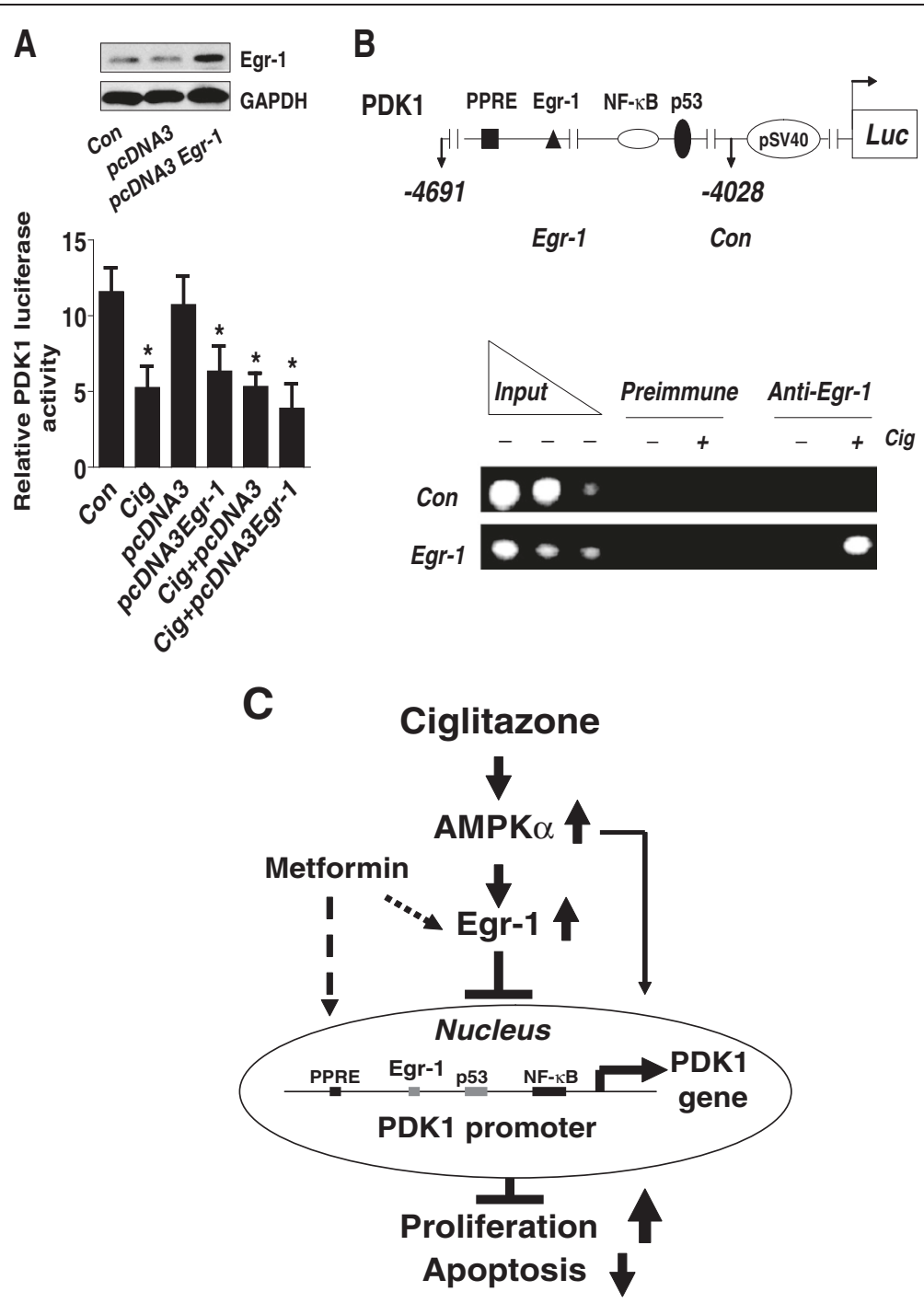

\section{Lung adenocarcinoma cells}

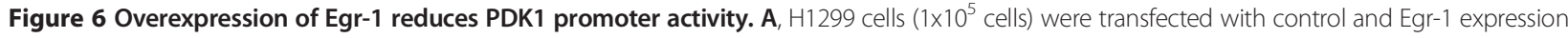
reporter constructs, and together with a wild type PDK1 promoter construct and an internal control Renilla Luciferase Reporter Vector as described in Material and Methods section for $24 \mathrm{~h}$, then treated with ciglitazone $(20 \mu \mathrm{M})$ for an additional $24 \mathrm{~h}$. The insert in upper panel represents Western blot results for Egr-1 protein. B, H1299 cells were lysed after exposure of ciglitazone $(20 \mu \mathrm{M})$ for $24 \mathrm{~h}$, and nuclei were isolated and then sonicated. Chromatin from $\mathrm{H} 1650$ cells was immunoprecipitated using antibodies against Egr-1 protein or preimmune serum (pre-immune). PCR analysis using primers surrounding the Egr-1 site shows that this DNA sequence ( -4392 to $-4402 \mathrm{bp}$ ) is specifically immunoprecipitated indicating that Egr-1 binds to endogenous DNA sites in the PDK1 promoter. A non- Egr-1 sequence was used as control. Aliquots of the chromatin were also analyzed before immunoprecipitation (input). C, Diagram demonstrates that ciglitazone inhibits PDK1 expression through AMPKa-mediated induction of Egr-1 protein expression and Egr-1 protein binding to the DNA sequence in the PDK1 gene promoter independent of PPARY. Activation of AMPKa enhances the effect of ciglitazone on Egr-1 and PDK1 protein expression. In turn, this results in inhibition of NSCLC cell proliferation.

using a commercially available kit (Invitrogen, Shanghai, China) in the Laboratory and Animal Center at Sun Yat-sen University in April 2010 and August 2012. Polyclonal antibodies specific for PDK1, phosphor-AMPK $\alpha$ (thr172) phosphor-p-SAPK/JNK (Thr183/Tyr185) and total AMPK $\alpha$ and SAPK/JNK were purchased from Cell Signaling (Beverly, MA). Polyclonal antibodies against PPAR $\gamma$, AMPK $\alpha$, p53, p65 and Egr-1 were purchased from Santa
Cruz Biotechnology, Inc (Santa Cruz, CA, USA). Ciglitazone, SP600125, GW9662, compound C, metformin and other chemicals were purchased from Sigma Aldrich (St. Louis, MO, USA) unless otherwise indicated.

\section{Western blot analysis}

Protein concentrations were determined by the Bio-Rad protein assay. Equal amounts of protein from whole cell 
lysates were solubilized in 2x SDS-sample buffer and separated on $10 \%$ SDS polyacrylamide gels. Membranes were incubated with antibodies against PDK1, PPARg phosphor-AMPK $\alpha$ (thr172) phosphor-p-SAPK/JNK (Thr183/Tyr185) and total AMPK $\alpha$ and SAPK/JNK, p53, p65 and Egr-1. The membranes were washed and incubated with incubation with a secondary goat antibody raised against rabbit IgG conjugated to horseradish peroxidase (Cell Signaling, Beverly, MA, USA). The membranes were washed again and transferred to freshly made ECL solution (Pierce, Rockford, IL, USA) for $1 \mathrm{~min}$, and exposed to X-ray film.

\section{MTT cell viability assay}

Cell viability was measured using the 3-(4, 5-dimethylthiazol-2- yl)-2, 5-diphenyltetrazolium bromide (MTT) assay. Briefly, NSCLC cells $\left(5 \times 10^{3}\right.$ cells/well $)$ were counted and seeded into a 96-well microtiterplate. The cells were treated with increasing concentrations of ciglitazone for up to $72 \mathrm{~h}$. After incubation, $10 \mu \mathrm{L}$ MTT solution $(5 \mathrm{~g} / \mathrm{L})$ was added to each well and incubated at $37^{\circ} \mathrm{C}$ for an additional $4 \mathrm{~h}$. Supernatant was removed, then $150 \mu \mathrm{L}$ DMSO was added to each well and oscillated for $10 \mathrm{~min}$. Absorbance at $490 \mathrm{~nm}$ was determined through the use of ELISA reader (Perkin Elmer, Victor X5, USA). Each experiment was repeated at least three times. Cell viability (\%) was calculated as (absorbance of test sample/ absorbance of control) $\times 100 \%$.

\section{CellTiter-Glo luminescent cell viability assay}

Human lung carcinoma cells were treated with compound $\mathrm{C}$ for $2 \mathrm{~h}$ or were transfected with control or Egr-1 siRNA or PDK1 expression vectors for $24 \mathrm{~h}$ before exposure of the cells to ciglitazone for an additional $24 \mathrm{~h}$ in 96-well plates in DMEM media with $0.5 \%$ FBS. Afterwards, cell viability was measured using the CellTiter-Glo Luminescent Cell Viability Assay kit (Promega, Shanghai, China) according to the instructions of the manufacturer.

\section{Detection of caspase-3/7 activity}

Enzymatic activity of caspase-3/7 was measured using the Caspase-Glo 3/7 Assay kit (Promega, Shanghai, China) according to the manufacturer's instruction. Briefly, NSCLC cells were seeded in 96-well plates and treated with or without $20 \mu \mathrm{M}$ of ciglitazone for $48 \mathrm{~h}$. Afterwards, the cells were lysed and incubated with $100 \mu \mathrm{L}$ of Apo-ONE Caspase-3/7 reagent (substrate and buffer in the ratio of $1: 100)$. After $1 \mathrm{~h}$ incubation in the dark at RT, the fluorescence of each well was measured at $485-520 \mathrm{~nm}$ by reading in an Epoch microplate reader (Biotek Instruments; Winooski, VT, USA).

\section{Treatment with AMPKa, PDK1, Egr-1 and PPARy small interfering RNA (siRNA)}

The siRNA human PDPK1 (EHU071261) was ordered from Sigma (Shanghai, China). The AMPK $\alpha$ (Cat No. sc-45312), Egr-1 siRNA (Cat No. sc-105070), PPAR $\gamma$ siRNA (Cat No. sc-29455), and control nonspecific siRNA oligonucleotides (Cat No. sc-37007) were purchased from Santa Cruz Biotechnology (Santa Cruz, CA, USA). For the transfection procedure, cells were grown to $60 \%$ confluence, and PDK1, Egr-1, and PPAR $\gamma$ and control siRNAs were transfected using the oligofectamine reagent (Invitrogen, Shanghai, China) according to the manufacturer's instructions. Briefly, Lipofectamine was incubated with serum-free medium for $10 \mathrm{~min}$., mixed with siRNA (80 $\mathrm{nM}$ ), incubated for $20 \mathrm{~min}$ at room temperature before the mixture was diluted with medium and added to cells. After culturing for $30 \mathrm{~h}$, cells were washed, resuspended in new culture media in the presence or absence of ciglitazone for an additional $24 \mathrm{~h}$ for Western Blot, cell growth, luciferase report assays and other experiments.

\section{Transient transfection assays}

The original human PDK1 promoter construct was a gift from Dr. Michalik at the University of Lausanne and have been reported previously [39]. The PDK1 promoter construct contains approximately 1500 base pairs of the 5 ' flanking region of the human PDK1 gene connected to the pGL3 basic luciferase reporter vector [39]. Briefly, NSCLC cells were seeded at a density of $5 \times 10^{5}$ cells/well in 6-well dishes and grown to $50-60 \%$ confluence. For each well, $2 \mu \mathrm{g}$ of the control or PPRE X3-TK-luc reporter (Addgene, plasmid 1015) [40], above PDK1 plasmid DNA constructs, or overexpression of PDK1 (pDONR223PDPK1) (Addgene plasmid 23801) [41] or Egr-1 expression vectors [obtained from Dr. Thomas Eling (NIEHS, USA) and have been reported previously] [42], with or without $0.2 \mu \mathrm{g}$ of the internal control phRL-TK Renilla Luciferase Reporter Vector were co-transfected into the cells with the oligofectamine reagent (Invitrogen, Shanghai, China). In parallel experiments, NSCLC cells transfected with Egr-1, PPAR $\gamma$, or control siRNAs ( $80 \mathrm{nM}$ each) for $30 \mathrm{~h}$ followed by exposed the cells to ciglitazone for an additional $24 \mathrm{~h}$. The preparation of cell extracts and measurement of luciferase activities were determined using the Dual-Luciferase Reporter Kit (Promega, Shanghai, China). Firefly luciferase activity was normalized with Renilla luciferase activity within each sample.

\section{Chromatin immunoprecipitation assay (ChIP)}

ChIP assays were performed as described by other study [43]. Briefly, cells were incubated in $1 \%$ formaldehyde for $10 \mathrm{~min}$ at $37^{\circ} \mathrm{C}$, quenched with $125 \mathrm{mmol} / \mathrm{L}$ glycine, lysed in SDS buffer with protease inhibitors (Roche), $0.5 \mathrm{mmol} / \mathrm{L}$ phenylmethyl-sulfonyl fluoride and sonicated. 
Fragmented chromatin was pre-cleared by adding salmon sperm-DNA/protein A-agarose beads. A portion of the supernatant was kept as "input" material. The remaining cleared chromatin was incubated overnight with or without $5 \mu \mathrm{g}$ of anti-Egr-1 antibody or normal human IgG (Upstate Biotechnology, Shanghai, China). DNA $(10 \mu \mathrm{g})$ from each immunoprecipitation was reserved for input controls. DNA was purified with QIAquick PCR purification column (QIAGEN Sciences, MA) and genomic sequences of interest were amplified by PCR using primers Egr-1 forward (-4392/-4402) 5' - GAGGGTGG ACACAGTTGAGTCAG-3' and reverse '5-TGGACAA CATTAGCAAGACCCTG-3'. A total of $2 \%$ of each IP was assayed by PCR using primers specific for the region of interest (218 bp).

\section{Statistical analysis}

All experiments were repeated a minimum of three times. All data were expressed as means $\pm \mathrm{SD}$. and then processed using SPSS10.0 software. Statistical significance was determined with Student's t test (two-tailed) comparison between two groups of data set. Asterisks shown in the figures indicate significant differences of experimental groups in comparison with the corresponding control condition $(\mathrm{P}<0.05$, see figure legends).

\section{Abbreviations}

PPARY: Peroxisome proliferator-activated receptors gamma;

PDK1: Phosphoinositide-dependent protein kinase 1; Egr-1: Early growth response-1; siRNA: Small interfering RNA; ChIP: Chromatin immunoprecipitation assay; AMPKa: AMP-activated protein kinase alpha; SAPKJJNK: Stress-activated protein kinase/c-Jun N-terminal kinase; NSCLC: Non-small cell lung cancer; PPRE: PPAR response elements; NF-kB: Nuclear factor-kB; TZDs: Thiazolinediones.

\section{Competing interest}

There is no potential conflict of interest or financial dependence regarding this publication.

\section{Authors' contributions}

SSH conceived of the study, participated in its design and coordination, and draft the manuscript. QT carried out the cell growth, siRNA, Western Blot assays, transfection and luciferase report assays. FZ participated in performed the cell viability, siRNA, transfection assays and protein expression experiments, SYZ involved in cell viability, protein expression and statistical analysis. JPC and ZYW provided agents, coordinated and critical read the manuscript. All authors read and approved the final manuscript.

\footnotetext{
Acknowledgments

We are grateful to Drs. Michalik and Desvergne (Center for Intergrative Genomics at University of Lausanne in Switzerland) for providing the PDK1 promoter constructs, Dr. William Hahn (Dana-Farber Cancer Institute, Boston, Massachusetts, USA.) for providing PDK1 expression vector and Dr. Thomas E Eling (NIEHS, USA) for providing the Egr-1 expression vector, and finally, Dr. Bruce M. Spiegelman for providing PPRE X3-Tk-luc reporter (Dana-Farber Cancer Institute, Massachusetts, USA). This work was supported in part by the Special Science and Technology Join fund from Guangdong Province-Guangdong Academy of Traditional Chinese Medicine (2012A032500011) and grant from the National Nature Scientific Foundation of China (81272614).
}

\section{Author details}

${ }^{1}$ University of Guangzhou Traditional Chinese Medicine, Guangdong Academy of Traditional Chinese Medicine, Guangdong Provincial Hospital of Chinese Medicine, Guangzhou, Guangdong Province, China 510120. ${ }^{2}$ Schoo of Chinese Medicine, Li Ka Shing Faculty of Medicine, University of Hong Kong, 10 Sassoon Road, Hong Kong, China 00852

Received: 7 November 2013 Accepted: 3 June 2014

Published: 13 June 2014

\section{References}

1. Lee CB, Stinchcombe TE, Rosenman JG, Socinski MA: Therapeutic advances in local-regional therapy for stage III non-small-cell lung cancer: evolving role of dose-escalated conformal (3-dimensional) radiation therapy. Clin Lung Cancer 2006, 8:195-202.

2. Dempke WC, Suto T, Reck M: Targeted therapies for non-small cell lung cancer. Lung Cancer 2010, 67:257-274.

3. Siegel R, Naishadham D, Jemal A: Cancer statistics, 2013. CA Cancer J Clin 2013, 63:11-30.

4. Tan NS, Michalik L, Desvergne B, Wahli W: Multiple expression control mechanisms of peroxisome proliferator-activated receptors and their target genes. J Steroid Biochem Mol Biol 2005, 93:99-105.

5. Choi JH, Banks AS, Kamenecka TM, Busby SA, Chalmers MJ, Kumar N, Kuruvilla DS, Shin Y, He Y, Bruning JB, Marciano DP, Cameron MD, Laznik D, Jurczak MJ, Schürer SC, Vidović D, Shulman Gl, Spiegelman BM, Griffin PR: Antidiabetic actions of a non-agonist PPARgamma ligand blocking Cdk5-mediated phosphorylation. Nature 2011, 477:477-481.

6. Terrasi M, Bazan V, Caruso S, Insalaco L, Amodeo V, Fanale D, Corsini LR, Contaldo C, Mercanti A, Fiorio E, Lo Re G, Cicero G, Surmacz E, Russo A: Effects of PPARgamma agonists on the expression of leptin and vascular endothelial growth factor in breast cancer cells. J Cell Physiol 2013, 228:1368-1374.

7. Li S, Zhou Q, He H, Zhao Y, Liu Z: Peroxisome proliferator-activated receptor gamma agonists induce cell cycle arrest through transcriptional regulation of Kruppel-like factor 4 (KLF4). J Biol Chem 2013, 288:4076-4084.

8. Cellurale C, Girnius N, Jiang F, Cavanagh-Kyros J, Lu S, Garlick DS, Mercurio AM, Davis RJ: Role of JNK in mammary gland development and breast cancer. Cancer Res 2012, 72:472-481.

9. Liang J, Mills GB: AMPK: a contextual oncogene or tumor suppressor? Cancer Res 2013, 73:2929-2935.

10. Cho KN, Sukhthankar M, Lee SH, Yoon JH, Baek SJ: Green tea catechin (-)-epicatechin gallate induces tumour suppressor protein ATF3 via EGR1 activation. Eur J Cancer 2007, 43:2404-2412

11. Gibbs JD, Liebermann DA, Hoffman B: Egr-1 abrogates the E2F-1 block in terminal myeloid differentiation and suppresses leukemia. Oncogene 2008, 27:98-106.

12. Bar-Shavit R, Turm H, Salah Z, Maoz M, Cohen I, Weiss E, Uziely B, Grisaru-Granovsky S: PAR1 plays a role in epithelial malignancies: transcriptional regulation and novel signaling pathway. IUBMB Life 2011, 63:397-402

13. Raimondi C, Falasca M: Targeting PDK1 in cancer. Curr Med Chem 2011, $18: 2763-2769$

14. Lu Z, Cox-Hipkin MA, Windsor WT, Boyapati A: 3-phosphoinositidedependent protein kinase-1 regulates proliferation and survival of cancer cells with an activated mitogen-activated protein kinase pathway. $\mathrm{Mol}$ Cancer Res 2010, 8:421-432.

15. Liu Y, Wang J, Wu M, Wan W, Sun R, Yang D, Sun X, Ma D, Ying G, Zhang N: Down-regulation of 3-phosphoinositide-dependent protein kinase-1 levels inhibits migration and experimental metastasis of human breast cancer cells. Mol Cancer Res 2009, 7:944-954.

16. Hann SS, Zheng F, Zhao S: Targeting 3-phosphoinositide-dependent protein kinase 1 by $\mathrm{N}$-acetyl-cysteine through activation of peroxisome proliferators activated receptor alpha in human lung cancer cells, the role of p53 and p65. J Exp Clin Cancer Res 2013, 32:43.

17. Gagliardi PA, di Blasio L, Orso F, Seano G, Sessa R, Taverna D, Bussolino F, Primo L: 3-phosphoinositide-dependent kinase 1 controls breast tumor growth in a kinase-dependent but Akt-independent manner. Neoplasia 2012, 14:719-731.

18. Wu J, Wu JJ, Yang LJ, Wei LX, Zou DJ: Rosiglitazone protects against palmitate-induced pancreatic beta-cell death by activation of autophagy via 5'-AMP-activated protein kinase modulation. Endocrine 2013, 44:87-98. 
19. Morrison A, Yan X, Tong C, Li J: Acute rosiglitazone treatment is cardioprotective against ischemia-reperfusion injury by modulating AMPK, Akt, and JNK signaling in nondiabetic mice. Am J Physiol Heart Circ Physiol 2011, 301:H895-H902.

20. Ramer R, Heinemann K, Merkord J, Rohde H, Salamon A, Linnebacher M, Hinz B: COX-2 and PPAR-gamma confer cannabidiol-induced apoptosis of human lung cancer cells. Mol Cancer Ther 2013, 12:69-82.

21. Peifer C, Alessi DR: Small-molecule inhibitors of PDK1. ChemMedChem 2008, 3:1810-1838

22. Plissonnier ML, Fauconnet S, Bittard H, Lascombe I: The antidiabetic drug ciglitazone induces high grade bladder cancer cells apoptosis through the up-regulation of TRAIL. PLOS One 2011, 6:e28354.

23. Moss PE, Lyles BE, Stewart LV: The PPARgamma ligand ciglitazone regulates androgen receptor activation differently in androgen-dependent versus androgen-independent human prostate cancer cells. Exp Cell Res 2010, 316:3478-3488.

24. Al-Alem L, Southard RC, Kilgore MW, Curry TE: Specific thiazolidinediones inhibit ovarian cancer cell line proliferation and cause cell cycle arrest in a PPARgamma independent manner. PLoS One 2011, 6:e16179.

25. Pestereva E, Kanakasabai S, Bright JJ: PPARgamma agonists regulate the expression of stemness and differentiation genes in brain tumour stem cells. Br J Cancer 2012, 106:1702-1712.

26. Han S, Roman J: Rosiglitazone suppresses human lung carcinoma cell growth through PPARgamma-dependent and PPARgamma-independent signal pathways. Mol Cancer Ther 2006, 5:430-437.

27. Hazra S, Batra RK, Tai HH, Sharma S, Cui X, Dubinett SM: Pioglitazone and rosiglitazone decrease prostaglandin E2 in non-small-cell lung cancer cells by up-regulating 15-hydroxyprostaglandin dehydrogenase. $\mathrm{Mol}$ Pharmacol 2007, 71:1715-1720.

28. Yang C, Jo SH, Csernus B, Hyjek E, Liu Y, Chadburn A, Wang YL: Activation of peroxisome proliferator-activated receptor gamma contributes to the survival of T lymphoma cells by affecting cellular metabolism. Am J Pathol 2007, 170:722-732.

29. Wang P, Dharmaraj N, Brayman MJ, Carson DD: Peroxisome proliferator-activated receptor gamma activation inhibits progesterone-stimulated human MUC1 expression. Mol Endocrinol 2010, 24:1368-1379.

30. Han EJ, Im CN, Park SH, Moon EY, Hong SH: Combined treatment with peroxisome proliferator-activated receptor (PPAR) gamma ligands and gamma radiation induces apoptosis by PPARgamma-independent up-regulation of reactive oxygen species-induced deoxyribonucleic acid damage signals in non-small cell lung cancer cells. Int J Radiat Oncol Biol Phys 2013, 85:e239-e248.

31. Kim BM, Maeng $\mathrm{K}$, Lee $\mathrm{KH}$, Hong SH: Combined treatment with the Cox-2 inhibitor niflumic acid and PPARgamma ligand ciglitazone induces ER stress/caspase-8-mediated apoptosis in human lung cancer cells. Cancer Lett 2011, 300:134-144

32. Tsai JS, Chen CY, Chen YL, Chuang LM: Rosiglitazone inhibits monocyte/ macrophage adhesion through de novo adiponectin production in human monocytes. J Cell Biochem 2010, 110:1410-1419.

33. Okami N, Narasimhan P, Yoshioka H, Sakata H, Kim GS, Jung JE, Maier CM, Chan PH: Prevention of JNK phosphorylation as a mechanism for rosiglitazone in neuroprotection after transient cerebral ischemia: activation of dual specificity phosphatase. J Cereb Blood Flow Metab 2013, 33:106-114.

34. Awuah PK, Rhieu BH, Singh S, Misse A, Monga SP: beta-Catenin loss in hepatocytes promotes hepatocellular cancer after diethylnitrosamine and phenobarbital administration to mice. PLoS One 2012, 7:e39771.

35. Shimoyamada H, Yazawa T, Sato H, Okudela K, Ishii J, Sakaeda M, Kashiwag K, Suzuki T, Mitsui H, Woo T, Tajiri M, Ohmori T, Ogura T, Masuda M, Oshiro $\mathrm{H}$, Kitamura $\mathrm{H}$ : Early growth response-1 induces and enhances vascular endothelial growth factor-A expression in lung cancer cells. Am J Pathol 2010, 177:70-83.

36. Myung DS, Park YL, Kim N, Chung CY, Park HC, Kim JS, Cho SB, Lee WS, Lee

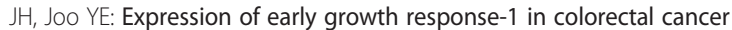
and its relation to tumor cell proliferation and apoptosis. Oncol Rep 2014, 31:788-794.

37. Ma Y, Cheng Q, Ren Z, Xu L, Zhao Y, Sun J, Hu S, Xiao W: Induction of IGF-1R expression by EGR-1 facilitates the growth of prostate cancer cells. Cancer Lett 2012, 317:150-156.
38. Chbicheb S, Yao X, Rodeau JL, Salamone S, Boisbrun M, Thiel G, Spohn D, Grillier-Vuissoz I, Chapleur Y, Flament S, Mazerbourg S: EGR1 expression: a calcium and ERK1/2 mediated PPARgamma-independent event involved in the antiproliferative effect of 15-deoxy-Delta12,14-prostaglandin J2 and thiazolidinediones in breast cancer cells. Biochem Pharmacol 2011, 81:1087-1097.

39. Di-Poi N, Tan NS, Michalik L, Wahli W, Desvergne B: Antiapoptotic role of PPARbeta in keratinocytes via transcriptional control of the Akt1 signaling pathway. Mol Cell 2002, 10:721-733.

40. Kim JB, Wright HM, Wright M, Spiegelman BM: ADD1/SREBP1 activates PPARgamma through the production of endogenous ligand. Proc Natl Acad Sci U S A 1998, 95:4333-4337.

41. Johannessen CM, Boehm JS, Kim SY, Thomas SR, Wardwell L, Johnson LA, Emery CM, Stransky N, Cogdill AP, Barretina J, Caponigro G, Hieronymus H, Murray RR, Salehi-Ashtiani K, Hill DE, Vidal M, Zhao JJ, Yang X, Alkan O, Kim S, Harris JL, Wilson CJ, Myer VE, Finan PM, Root DE, Roberts TM, Golub T, Flaherty KT, Dummer R, Weber BL: COT drives resistance to RAF inhibition through MAP kinase pathway reactivation. Nature 2010, 468:968-972.

42. Moon Y, Bottone FG Jr, McEntee MF, Eling TE: Suppression of tumor cell invasion by cyclooxygenase inhibitors is mediated by thrombospondin-1 via the early growth response gene Egr-1. Mol Cancer Ther 2005, 4:1551-1558.

43. Zheng Y, Ritzenthaler JD, Sun X, Roman J, Han S: Prostaglandin E2 stimulates human lung carcinoma cell growth through induction of integrin-linked kinase: the involvement of EP4 and Sp1. Cancer Res 2009, 69:896-904.

doi:10.1186/1476-4598-13-149

Cite this article as: Hann et al:: Repression of phosphoinositide-dependent protein kinase 1 expression by ciglitazone via Egr-1 represents a new approach for inhibition of lung cancer cell growth. Molecular Cancer 2014 13:149.

\section{Submit your next manuscript to BioMed Central and take full advantage of:}

- Convenient online submission

- Thorough peer review

- No space constraints or color figure charges

- Immediate publication on acceptance

- Inclusion in PubMed, CAS, Scopus and Google Scholar

- Research which is freely available for redistribution 